\title{
Concentração sérica de progesterona em bezerras da raça nelore e mestiças tratadas com progesterona em veículo de liberação lenta
}

[Serum progesterone concentration in Nelore and crossbreed heifers treated with long-acting progesterone]

\author{
F.P.C. Lima ${ }^{1}$, A. P. Marques $J^{1 *}$, R.H. Douglas ${ }^{2}$, M. Houri Neto ${ }^{1}$ \\ ${ }^{1}$ Escola de Veterinária - UFMG \\ Caixa Postal 567 \\ 30123-970 - Belo Horizonte, MG. \\ ${ }^{2}$ B.E.T Labs - RJ/Lexington - KY - USA
}

\begin{abstract}
RESUMO
Avaliaram-se a eliminação da progesterona em veículo de liberação lenta $\left(\mathrm{P}_{4} \mathrm{LA}\right)$ em animais zebus e mestiços e sua potencial aplicabilidade em programas de sincronização de estro, utilizando-se 60 bezerras, 30 da raça Nelore e 30 mestiças (Gir x Holandês), entre 120 e 150 dias de idade e peso médio de $150 \mathrm{~kg}$. Em cada grupo experimental as bezerras foram divididas em três subgrupos (G) de 10 animais, sendo GI = controle (tratado com $5 \mathrm{ml}$ de solução fisiológica por via intramuscular); GII = tratado com 450mg $\mathrm{P}_{4} \mathrm{LA}(3 \mathrm{ml} \mathrm{IM})$; e GIII = tratado com 750mg $\mathrm{P}_{4} \mathrm{LA}(5 \mathrm{ml} \mathrm{IM})$. Amostras de sangue foram coletadas no dia zero, 7 e 13 (D0, D7 e D13) e procedeu-se à análise hormonal por radioimunoensaio de fase sólida. A progesterona de ação prolongada $\left(\mathrm{P}_{4} \mathrm{LA}\right)$, administrada por via intramuscular, manteve-se por 13 dias na corrente sangüínea em concentrações superiores a $1 \mathrm{ng} / \mathrm{ml}$. As doses de $450 \mathrm{mg}$ e $750 \mathrm{mg}$ de $\mathrm{P}_{4} \mathrm{LA}$ não ocasionaram efeitos adversos sistêmicos clinicamente perceptíveis, e o metabolismo da $\mathrm{P}_{4} \mathrm{LA}$ foi mais lento nas bezerras Nelore, cuja concentração de progesterona foi maior na corrente sangüínea do que nas bezerras mestiças.
\end{abstract}

Palavras-chave: bezerra, progesterona de liberação lenta, concentração de progesterona

\begin{abstract}
The clearance of long-acting progesterone in microspheres $\left(P_{4} L A\right)$ in zebu animals and its potential for use in estrus synchronization were evaluated using 30 Nelore and 30 crossbreed (Holstein $x$ zebu) heifers, with aging between 120 to 150-day-old and weighting 150kg in average. For each breed the animals were divided into three groups of ten animals each, GI= control group treated with saline; GII= treated with 450mg of $P_{4} L A$; and GIII= treated with $750 \mathrm{mg}$ of long-acting progesterone $\left(P_{4} L A\right)$. Blood samples were colleted on days 0,7 and 13 and analysed for progesterone using radioimmunoassay in solid phase. The serum concentration of progesterone was different on days 0,7 and 13 in relation to the dose of $P_{4} L A$ given. All treated animals presented basal values for progesterone on day 0 , increased on day 7 and decreased on day 13, but with values over $1 \mathrm{ng} / \mathrm{ml}$. The results show that the drug was absorbed rapidly after its administration and remained in satisfactory concentration in the circulation until day 13. The average total concentration of serum progesterone was higher in Nelore heifers when compared to the concentration in crossbreed ones, indicating difference in the metabolism of the drug between the two genetic groups.
\end{abstract}

Keywords: heifers, long-acting progesterone, progesterone concentration

Recebido em 26 de julho de 2005

Aceito em 30 de março de 2007

*Autor para correspondência (corresponding author)

E-mail: ampinho@ufmg.br 


\section{INTRODUÇÃO}

Diferenças morfológicas são descritas entre $B o s$ taurus indicus e Bos taurus taurus, as quais podem influenciar a resposta aos regimes de sincronização de estro (Baruselli et al., 2004). Randel (1989) observou que corpos lúteos de animais zebu são menores em tamanho e em quantidade de progesterona por grama de tecido luteal comparado a corpos lúteos de animais Bos taurus taurus, o que pode refletir na diminuição das concentrações de progesterona circulante em animais zebuínos (Segerson et al., 1984). A endocrinologia reprodutiva do Bos taurus indicus tem um padrão diferenciado do já conhecido na literatura para o Bos taurus taurus. Fêmeas Bos taurus indicus são pouco responsivas ao estímulo estrogênico, exibindo estro de menor duração e intensidade, podendo apresentar uma redução na capacidade de secreção do hormônio luteinizante (LH). A onda pré-ovulatória de $\mathrm{LH}$ em zebuínos é baixa e inicia-se precocemente no ciclo estral em relação ao momento da ovulação, podendo ocasionar atraso na maturidade sexual e falha no crescimento folicular e na ovulação (Randel, 1984). Além disso, o Bos taurus indicus apresenta sensibilidade aumentada a gonadotrofinas exógenas e falhas na responsividade do ovário a hormônios exógenos (Munro, 1986).

A concentração de progesterona $\left(\mathrm{P}_{4}\right)$ apresenta variações cíclicas durante o ciclo estral que refletem as fases de crescimento, manutenção e regressão do corpo lúteo. A concentração plasmática de $\mathrm{P}_{4}$ está relacionada com sua produção e liberação pelo corpo lúteo e suas taxas de metabolização e eliminação, que podem ser influenciadas pelo fluxo sangüíneo, disponibilidade de precursores e fatores luteotróficos (Viana et al., 1999). Interações endócrinas entre o hipotálamo, a hipófise anterior, os ovários e o útero são essenciais para o controle do ciclo estral e a sincronização do estro em bovinos (Mihm et al., 2002). Em bovinos, a indução e a sincronização artificial do estro e da ovulação combinam o uso de vários hormônios como progestágenos, estradiol, GnRH e agentes luteóliticos (Ryan et al., 1999).

Protocolos eficientes de tratamento e sincronização de estro são cada vez mais procurados (Rathbone et al., 1998). O uso da progesterona com o intuito de sincronizar o estro em bovinos está baseado na capacidade que a progesterona tem de suprimir a freqüência de pulsos de LH, reduzindo o desenvolvimento do folículo dominante e prevenindo a ovulação (Adams et al., 1992; Macmillan et al., 2003).

A demanda para o desenvolvimento de uma formulação de progesterona de longa ação em veículo biodegradável para uso nas espécies domésticas é crescente (Rathbone et al., 1998). Foi demonstrado que uma única aplicação intramuscular de um produto à base de progesterona, em microesferas biodegradáveis, possibilita controlar a ovulação. Este tipo de produto faz com que, em uma única administração, a concentração sérica desejável de progesterona seja mantida por dias ou meses (Blanchard et al., 1992; Burns et al., 1993; Fleury et al., 1993; Whisnant e Burns, 2002).

Whisnant e Burns (2002) mostraram, em novilhas pré-púberes, que a preparação em microesferas com $625 \mathrm{mg}$ de progesterona e $50 \mathrm{mg}$ de estradiol manteve a concentração sérica de progesterona semelhante à da fase luteal por 12-13 dias, além de ser capaz de desencadear o início do ciclo estral nesses animais, com ou sem o uso combinado de estradiol. Bringel et al. (2003) realizaram experimento no qual foi testado um produto à base de progesterona de longa ação (BioRelease $\left.\mathrm{P}_{4} \mathrm{LA} 150\right)^{\circledR 1}$. Duas doses de progesterona natural $(750 \mathrm{mg}$ e $1500 \mathrm{mg}$ ), em veículo não aquoso e de baixa viscosidade (BioRelease Delivery SystemTM) ${ }^{\circledR 1}$, foram administradas por via intramuscular em éguas anovulatórias. As concentrações de progesterona sérica mantiveram-se elevadas (acima de $1,0 \mathrm{ng} / \mathrm{ml}$ ) durante 10 a 11 dias, com uma única administração da dose de $1500 \mathrm{mg} / \mathrm{ml}$ e por 5 a 7 dias com uma única dose de $750 \mathrm{mg} / \mathrm{ml}$.

O objetivo deste estudo foi avaliar a concentração sérica de progesterona em bezerras Nelores e mestiças, tratadas por via intramuscular, com progesterona em veículo de liberação lenta.

\section{MATERIAL E MÉTODOS}

O experimento foi realizado na Fazenda Bom Jardim, município de Rio Vermelho, Minas

${ }^{1}$ B.E.T Labs - RJ/Lexington, EUA 
Gerais, entre março e abril de 2004. Foram utilizados dois módulos: no módulo I, utilizaramse 30 bezerras mestiças (Gir x Holandês), entre 120 e 150 dias de idade e, no módulo II, 30 bezerras Nelore de mesma idade. As bezerras Nelores foram mantidas em condição padrão de manejo em pasto (Brachiaria decumbens) e somente separadas das mães no momento da coleta de sangue, no início da manhã. As bezerras mestiças ficavam no pasto, separadas das mães. Eram amamentadas logo após as ordenhas ( $2 \mathrm{x}$ ao dia). Nelas a coleta de sangue ocorreu após a ordenha da manhã. Em cada módulo, os animais foram divididos em três grupos $(\mathrm{G})$ de 10 animais, sendo GI = controle, tratado com $5 \mathrm{ml}$ de solução fisiológica por via intramuscular; GII = tratado com $450 \mathrm{mg} \mathrm{P}_{4} \mathrm{LA}^{2}$ $(3 \mathrm{ml} \mathrm{IM})$; e GIII = tratado com $750 \mathrm{mg} \mathrm{P}_{4} \mathrm{LA}(5 \mathrm{ml}$ IM). No dia zero (D0), após a coleta de sangue, procedeu-se à aplicação de dose única de salina ou $\mathrm{P}_{4} \mathrm{LA}$, segundo o tratamento para cada grupo. Amostras de sangue foram também coletadas nos dias sete (D7) e 13 (D13), sempre no mesmo horário.

O soro obtido das amostras de sangue foi acondicionado, em duplicata, em eppendorfs de $1,5 \mathrm{ml}$ e imediatamente congelado a $-20^{\circ} \mathrm{C}$, permanecendo estocado até o processamento. A análise hormonal foi feita por radioimunoensaio de fase sólida ${ }^{3}$.

O delineamento experimental foi inteiramente ao acaso com parcela subdividida. Os valores de progesterona sérica foram submetidos à análise de variância, e as diferenças entre as médias foram comparadas pelo teste "t de Student" $(\mathrm{P}<0,05)$, com as médias das concentrações plasmáticas sendo transformadas em log (X) (Sampaio, 2002).

\section{RESULTADOS E DISCUSSÃO}

As concentrações séricas de progesterona nos dias zero, 7 e 13 são apresentadas na Tab. 1 .

As concentrações séricas de progesterona $\left(\mathrm{P}_{4}\right)$ foram diferentes entre os tratamentos GII e GIII. A análise permitiu concluir que a eliminação da $\mathrm{P}_{4} \mathrm{LA}$ apresentou fases bem distintas e marcantes, sendo caracterizada por aumento após a aplicação seguida

${ }^{2} \mathrm{P}_{4} \mathrm{LA}$ (progesterona de ação prolongada) - BioRelease Technologies LLC of Lexington, EUA

${ }^{3}$ DPC (coat-a-count) - Diagnostic Products Corporation - Los Angeles, EUA de diminuição no sangue aos 13 dias, indicando que o fármaco foi bem absorvido e eliminado pelo organismo.

O D0 foi utilizado como um referencial das concentrações de $\mathrm{P}_{4}$ em bezerras, possibilitando inferir que as concentrações do hormônio são baixas não interferindo nos resultados após a aplicação dos tratamentos. A concentração sérica de progesterona não diferiu entre os tratamentos GI, GII e GIII no dia da aplicação dos tratamentos (D0), o que era esperado. A permanência da $\mathrm{P}_{4} \mathrm{LA}$ por 13 dias em concentrações superiores a $1 \mathrm{ng} / \mathrm{ml}$ mostrou-se relevante do ponto de vista farmacológico, sinalizando seu potencial de uso como uma nova alternativa em programas de sincronização de estro, considerando que os métodos e protocolos usados atualmente em programas comerciais não mantêm a concentração de progesterona por período semelhante ao encontrado nesse experimento, exigindo repetição de doses e um tempo maior no manejo com os animais.

Os resultados do presente trabalho são similares aos encontrados por Whisnant e Burns (2002), que verificaram em seu estudo com novilhas que as concentrações de $\mathrm{P}_{4}$ em preparação de microesferas mantiveram-se elevadas por 12-13 dias, sendo no D2 de 4-5ng/ml, no D7 de 4ng/ml e no D13 abaixo de $1 \mathrm{ng} / \mathrm{ml}$.

O GI teve a finalidade de comprovar que as bezerras utilizadas no experimento não apresentaram ciclicidade ovariana, pois as concentrações de progesterona foram em torno de $1 \mathrm{ng} / \mathrm{ml}$, sinalizando que os animais ainda não estavam com completa funcionalidade dos órgãos do sistema genital e que o sistema neuroendócrino não estava amadurecido para que as interações hormonais pudessem estar ocorrer.

Considerando os tratamentos GII e GIII em função do tempo observado, pode-se concluir que as concentrações de progesterona têm padrão semelhante, apresentando aumento na concentração do D0 ao D7 e, em seguida, diminuição do D7 ao D13, indicando que tanto a dose de $450 \mathrm{mg}$ quanto a de $750 \mathrm{mg}$ de $\mathrm{P}_{4} \mathrm{LA}$ são eficazes em promover o aumento na concentração de progesterona. Concluise que, nas condições deste experimento, a dose de $\mathrm{P}_{4} \mathrm{LA}$ com concentração mais baixa seria suficiente para promover o efeito desejado na ciclicidade ovariana, o que deve ser confirmado em animais adultos, considerando seu perfil metabólico. 
Tabela 1. Médias e desvios-padrão da concentração de progesterona $(\mathrm{ng} / \mathrm{ml})$ em função do tipo de tratamento e dia da mensuração em bezerras Nelore e mestiças

\begin{tabular}{lcccc}
\multicolumn{1}{c}{ Tratamento } & $\begin{array}{c}\text { Número de } \\
\text { animais }(\mathrm{n})\end{array}$ & $\begin{array}{c}\text { Dia } \\
(\mathrm{D} 0)\end{array}$ & $\begin{array}{c}\text { Dia } \\
(\mathrm{D} 7)\end{array}$ & $\begin{array}{c}\text { Dia } \\
(\mathrm{D} 13)\end{array}$ \\
\hline GI= solução fisiológica $(5 \mathrm{ml})$ & 20 & $0,67 \mathrm{bA} \pm 0,54$ & $1,56 \mathrm{aB} \pm 2,19$ & $0,67 \mathrm{bB} \pm 0,77$ \\
& 20 & $1,04 \mathrm{bA} \pm 0,94$ & $5,01 \mathrm{aA} \pm 2,82$ & $1,16 \mathrm{bA} \pm 0,94$ \\
$\mathrm{GII}=\mathrm{P}_{4} \mathrm{LA} 450 \mathrm{mg}(3 \mathrm{ml})$ & 20 & $1,02 \mathrm{cA} \pm 1,56$ & $6,16 \mathrm{aA} \pm 2,47$ & $1,98 \mathrm{bA} \pm 1,66$ \\
$\mathrm{GIII}=\mathrm{P}_{4} \mathrm{LA} 750 \mathrm{mg}(5 \mathrm{ml})$ & & &
\end{tabular}

Valores seguidos por letras distintas minúsculas na linha e distintas maiúsculas na coluna diferem entre si $(\mathrm{P}<0,05)$

Estes resultados devem ser considerados como um estudo preliminar, ressaltando que os animais utilizados não apresentavam função reprodutiva totalmente desenvolvida e ativa, o que foi metodologicamente favorável para verificar o perfil de absorção e eliminação da $\mathrm{P}_{4} \mathrm{LA}$ sem a interferência de progesterona endógena, como base para experimentos com animais adultos e reprodutivamente funcionais.

O presente estudo caracterizou o padrão das concentrações séricas de progesterona em bezerras Nelore e mestiças (Tab. 2). As bezerras Nelore apresentaram concentração média de progesterona circulante de $2,87 \mathrm{ng} / \mathrm{ml}$, superior à encontrada para bezerras mestiças, de $1,40 \mathrm{ng} / \mathrm{ml}$ $(\mathrm{P}>0,05)$.

Os resultados sinalizam que o efeito do tratamento com $\mathrm{P}_{4} \mathrm{LA}$ e os elevados valores das concentrações séricas de progesterona observados nas bezerras Nelore podem estar relacionados a um metabolismo mais lento da progesterona. Nas bezerras mestiças o metabolismo pode ser mais intenso, resultando em concentrações mais baixas de progesterona. $\mathrm{O}$ metabolismo entre as raças e até mesmo entre indivíduos pode ser diferente, considerando-se fatores genéticos e ambientais, como manejo nutricional e manejo de mamadas e possíveis interações entre eles.

Diferenças endócrinas entre animais Nelore e mestiços, já sinalizadas na literatura para animais reprodutivamente funcionais, assemelham-se aos resultados encontrados neste trabalho, que indicam que as concentrações séricas de progesterona foram influenciadas pelo grupo genético, o que vem de encontro com o exposto na literatura com relação à diferença nas concentrações de $\mathrm{P}_{4}$ e na responsividade a hormônios exógenos entre Bos taurus indicus e Bos taurus taurus (Randel, 1984; Munro, 1986).

Os resultados deste trabalho são semelhantes aos encontrados por Carvalho (2004), que estudou a concentração de progesterona em novilhas Bos taurus indicus, Bos taurus indicus x Bos taurus taurus e Bos taurus taurus com o uso do dispositivo intravaginal de $\mathrm{P}_{4}$ (CIDR-B) e verificou que novilhas Bos taurus indicus tiveram concentrações séricas de $\mathrm{P}_{4}$ mais elevadas. No entanto, o autor não aventou qualquer hipótese sobre a fisiologia dos animais estudados para justificar seus resultados. O manejo diferenciado das raças também pode ser considerado, como o tipo de nutrição que as bezerras Nelore e mestiça receberam e sua correlação com possíveis efeitos no metabolismo da droga.

Dos fatores mencionados, o manejo de mamadas pode ser considerado relevante para $o$ metabolismo mais lento da $\mathrm{P}_{4} \mathrm{LA}$ na bezerra Nelore, com maior número de mamadas ao longo do dia, pois permaneceram por mais tempo com as mães. Na bezerra mestiça, a menor freqüência de mamadas e o consumo de alimentos concentrados provavelmente influenciaram no aumento da eliminação da progesterona.

O local usado para aplicação de uma droga pode influenciar consideravelmente o padrão de liberação e sua subseqüente concentração na corrente sangüínea (Rathbone et al.; 2001). No presente trabalho, o protocolo de aplicação única, por via intramuscular e em veículo biodegradável, resultou no padrão de liberação da progesterona em que a concentração de $\mathrm{P}_{4}$ apresentou aumento após a aplicação, chegando a valores entre 5 a $6 \mathrm{ng} / \mathrm{ml}$ no D7, diminuindo até valores basais próximos a $1 \mathrm{ng} / \mathrm{ml}$ no D13. A 
queda na concentração de progesterona não ocorreu de forma brusca, pois a progesterona apresentou diminuição diferenciada para os dias medidos, sinalizando para a praticidade e a possibilidade de seu uso em programas comerciais de sincronização de estro.

\section{CONCLUSÕES}

$\mathrm{O}$ uso de $\mathrm{P}_{4} \mathrm{LA}$ é metodologicamente favorável para verificar o perfil de absorção e eliminação da $\mathrm{P}_{4} \mathrm{LA}$ sem a interferência de progesterona endógena. Bezerras Nelore e mestiças respondem de forma diferenciada ao tratamento com $\mathrm{P}_{4} \mathrm{LA}$.

\section{REFERÊNCIAS BIBLIOGRÁFICAS}

ADAMS, G.P.; MATTERI, R.L.; KASTELIC, J.P. et al. Association between surges of folliclestimulating hormone and the emergence of follicular waves in heifers. J. Reprod. Fertil., v.94, p.177-188, 1992.

BARUSELLI, P.S.; REIS, E.L.; MARQUES, M.O. et al. The use of hormonal treatments to improve reproductive performance of anestrous beef cattle in tropical climates. Anim. Reprod. Sci., v.82-83, p.479-486, 2004.

BLANCHARD, T.L.; VARNER, D.D.; BURNS, P.J. et al. Regulation of estrous and ovulation in mares with progesterone and estradiol biodegradable microspheres with or without $\mathrm{PGF}_{2 \alpha \text {, }}$. Theriogenology, v. 38, p.1091-1106, 1992.

BRINGEL, B.A.; JACOB, J.C.F.; ZIMMERMAN, M. et al. Biorelease progesterone LA 150 and its application to overcome effects of premature luteolysis on progesterone levels in mares. Rev. Bras. Reprod. Anim., v.27, p.498-500, 2003.

BURNS, P.J.; STEINER, D.V.M.; SERTICH, P.L. et al. Evaluation of biodegradable microspheres for the controlled release of progesterone and estradiol in an ovulation control program for cycling mares. Equine Nutr. Phys. Soc., v.13, p.521-524, 1993.

CARVALHO, J.B.P. Sincronização da ovulação com dispositivo intravaginal de progesterona $\left(C I D R^{\circledR}\right)$ em novilhas Bos indicus, Bos indicus $\mathrm{x}$ Bos taurus e Bos taurus. 2004, 122f. Tese (Doutorado) - Faculdade de Medicina Veterinária e Zootecnia, Universidade de São Paulo, São Paulo.

FLEURY, J.J.; COSTA-NETO, J.B.; BURNS, P.J. Regulation of estrus and ovulation in cyclic mares with progesterone and estradiol biodegradable microspheres: effects of different doses of estradiol. Equine Nutr. Phys. Soc., v.13, p.525-528, 1993.

MACMILLAN, K.L.; SEGWAGWE, B.V.E.; PINO, C.S. Associations between the manipulation of patterns of follicular development and fertility in cattle. Anim. Reprod. Sci., v.78, p.327-344, 2003.

MIHM, M.; CROWE, M.A.; KNIGHT, P.G. et al. Follicle wave growth in cattle. Reprod. Dom. Anim., v.37, p.191-200, 2002.

MUNRO, R.K. The superovulatory response of Bos Taurus and Bos indicus cattle following treatment with follicle stimulating hormone and progesterone. Anim. Reprod. Sci. v.11, p.91-97, 1986.

RANDEL, R.D. Endocrine aspects of zebu cow. Rev. Bras. Reprod. Anim., v.1, supl., p.1-26, 1989.

RANDEL, R.D. Seasonal effects on female reproductive functions in the bovine (Indian breeds). Theriogenology, v.21 p. 170-185, 1984.

RATHBONE, M.J.; KINDER, J.E.; FIKE, C. et al. Recent advances in bovine reproductive endocrinology and physiology and their impact on drug delivery system design for the control of the estrous cycle in cattle. Adv. Drug Del. Rev., v. 50, p.277-320, 2001.

RATHBONE, M.J.; MACMILLAN, K.L.; INSKEEP, K. et al. Fertility regulation in cattle. $J$. Contr. Rel., v. 54, p.117-148, 1998.

RYAN, D.P.; GALVIN, J.A.; O'FARRELL, K.J. Comparison of oestrus synchronization regimens for lactating dairy cows. Anim. Reprod. Sci., v.56, p.153-168, 1999.

SAMPAIO, I.B.M. Estatística aplicada à experimentação animal. 2.ed. Belo Horizonte: FEPMVZ, 2002. 265p.

SEGERSON, E.C.; HANSEN, T.R.; LIBBY, D.W. et al. Ovarian and uterine morphology and function in Angus and Brahman cows. J. Anim. Sci., v.59, p.1026-1046, 1984.

VIANA, J.H.M.; FERREIRA, A.M.; SÁ, W.F. et al. Características morfológicas e funcionais do corpo lúteo durante o ciclo estral em vacas da raça Gir. Arq. Bras. Med. Vet. Zootec., v.51, p.251-256, 1999.

WHISNANT, C.S.; BURNS, P.J. Evaluation of steroid microspheres for control of estrus in cows and induction of puberty in heifers. Theriogenology, v.58, p.1229-1235, 2002. 